\title{
Look at the Body of the Japanese Culture from the Movie "Departures"
}

\author{
Xiuli Yan \\ College of Foreign Languages, Hebei University of Technology, Tianjin 30000, China
}

Keywords: "Departures", Japan, The main body culture

\begin{abstract}
The American academy of film festival in 2009, the Japanese movie "departures" won the award for best foreign language film, as the Japanese film won an Oscar for the first time in the history of the cinema. The film has a profound cultural connotation, reveals the cultural conflict between east and west, in a certain degree of Oriental traditional culture inheritance and carries forward. Here in this paper, aiming at "departures" in the subject reflects the Japanese culture to carry on the analysis, the audience to understand the cultural connotation of this work provide certain help.
\end{abstract}

\section{Introduction}

Oscar film festival in 2009, the Japanese movie "departures" was able to get the judges agree, beat the calls for higher other films, the most important reason is that it' $\mathrm{s}$ on the processing of cultural details. "Departures" with extremely small brush strokes to show the audience the native culture of Japan, on the premise of beyond religion, by using soft, humor and inspire the audience to rethink and know life and death, extremely powerful and appeal, thought-provoking. Therefore, this article "departures" in Japan the main culture research as a breakthrough point, analyzes the main culture of life and death consciousness and the ceremony of the plot, hopes to be helpful to study of this movie.

\section{"Departures" in the Japanese culture reflected by the consciousness of life and death}

Japan as a land area smaller islands, is not only a large population, and the relative lack of resources, frequent geological disasters. Although these has had an impact on the development of Japanese society, but also led the Japanese to death with a more detached of awareness. In this issue, the Japanese love of cherry blossom is a very good proof. Cherry blossom in Japanese occupy the important position in life and literature, the vast majority of the film will insert the image of cherry blossoms, "departures" and so, to performance of cherry blossoms fleeting moments of life, to guide the audience insight into the true meaning of life.

\section{Japan's funeral culture}

Japan's funeral culture is closely related to the profession departures, the protagonist in the movie because of career in this the only in specific work situations created of a series of comprehension and reflection on life and death. In Japanese society, the people engaged in the work of departures for every day in the face of body, is considered by the people around is dirty, scorn. "Departures" hero is under extreme resistance, was forced to enter into this industry, and in the face of the fear of death at the same time, has been misunderstood by friends and family and forsaken, his pain, because of this inferiority, caused great mental pressure, painstaking work [1]. However, in the work, and it has been the league the subtle influence of Sasaki, can calm accept work gradually, and realize the essence of life, in the process of departures also understanding of departures from the work, think the shoulder the important mission, is worthy of respect.

In "departures," departures career has not only make up for the dead, the more important is through the makeup, let the dead after death can enjoy eternal beauty, is a grateful for the deceased to life, show a kind of respect for the dead and the human nature concern. And that is Japan's funeral culture connotation. The Japanese in the subconscious to death with a beautiful vision hope you can like as beautiful cherry blossoms slide of the die. As what the Japanese called "the art of the no more noble than death, death is another kind of life". Japanese Buddhism believes in the thoughts of death, in their thoughts, death is a kind of impermanence, if lost the death, life is unable to killing. "Departures" at the beginning of the film hero realize can see the kind of beauty is to use the process 
of suicide, this way of suicide will complete damage caused by the characteristic of the body of the dead, but after the departures of make-up work, the dead remain serene and beautiful state, maximum maintained the dignity, is a kind of respect for life.

\section{The view of life and death in Japan}

The Japanese discourse about death with Haruki Murakami commonly the argument of "Norwegian wood" is a typical representative: death is not the opposite of life, itself as an important part of life, which reflects the Japanese detached view of death [2]. Is affected by the Japanese society and culture, "departures" in the convey of ideas as no death is a kind of taboo, but as a social public often come into contact with the ordinary things to discuss, the film even more with a kind of soft warmth of the scene shows the dramatis personae's farewell when loved ones die. In a promotional video movie is such a scenario, when the old man died after the relatives are way to say goodbye to the old man with a kiss on the old man body, when the old man face paint full after the last, sons and daughters to commemorate the death of the old man with a group, and thanks to my father's company over the years.

In relations between life and death, the Japanese there is also a unique view of life and death it had two of the world, unable to cross in the Japanese thought into the concept of the linkage between the two important stages, that is to say, the end is the beginning of the death of life, the beginning of the death is also the continuation of life. Here, death is not the eternal silence in the traditional sense, but rather a flow oriented transformation, as long as the fire of the soul has not been put out, it can get eternal life on earth. In the minds of the Japanese, the birth and death of these two kinds of state can't be anything blocking and isolation, even in a certain cycle level there are similarities. View level, even in the narrow sense of literature also is a kind of Japanese unique spiritual culture. Study Japanese and interpretation of life and death, are not able to completely separated, both between life and death but think there must be a kind of sick to death, and from death to life cycle of change. This is the life and death in Japanese literature classic unified concept of life and death.

In the movie of "departures", there is a classic picture of life and death to the Japanese concept made a profound interpretation of drunk, funeral home staff in a final farewell to the wife of bath is obtained when the feeling of life and death, think gone does not mean an end, but lost it may be a kind of transcendence, death is a door open, through the door, can go to the next life's journey. And departures oneself is the door of the gatekeeper, whenever a person come over, he help them dress, and send blessings for them, looking forward to the next meet [3]. The film's protagonist enlightened in contact departures for the first time met an already highly decomposed body, in the face of the fear of death and physical disgust the spirit was hit. But is its confused about what to do, see the fish in the river in order to survive and reproduce upstream, and some dead fish washed falls and this knowing that the spirit of death is still going to hero brings a certain impact. "Fish are born like this," the "natural" it is through natural reproduction presentation to the audience, in order to get a new, you must pay the cost of death, the value of death is in the freshmen can get full embodiment. Fish without a sense of thinking and death can be selected for reproduction, for a new life, and people, and now that death is a stage in life is inevitable, it should face, eternal life to death.

At the same time, the hero realize at the time of his father came, in some detail shows the image of father in the sublimation, father's hands tightly holding the small stones, to realize not only touched, forgive his father, also let its leads to a new understanding of life. Him for a moment to understand the true meaning of the application, it will be small stones in his pregnant wife belly, suggests in his mind, the child is the father's blood, is a kind of the cycle of life, also let the audience feel in watching a deep regret of death as well as to the new anticipation and joy, and then to death in the film more profound thought connotation, is the sublimation of connotation for film as a whole. Here, the film to the audience clearly illustrates its central idea, which should be the correct view of death, comfortable with yourself and side people death, only then can we truly live free and easy and strong [4]. In Japan's eyes, a man's life is like gorgeous Sakura, open our best blooming brilliantly, die also want beautiful, become eternal. So the Japanese emphasize people should treasure the living time,, every day to live flavor, even if the real face of death, should also maintain a normal state of mind, to die with dignity. "Life wonderful, the death of the detachment" is what the Japanese have been hope for 
ideal life state of the Japanese people in the pursuit of enjoying life in the process of play to the value of life, and the enjoyment of life and value in the love of career and life and dedication to the society, it is explained in essentially the Japanese to probe the inner drive of striving for perfection in all things.

\section{The plot of ceremony in Japanese culture}

The movie departures also profound subject reflects the Japanese culture ceremony in the plot. Ritual culture is one of the most important elements of Japanese culture, whether its tea culture, flower culture, or kendo culture, should be in strict accordance with the relevant ceremony to complete the program. Movie "departures," repeated depict the departures of departures for the dead is really work scenarios, with meticulous brushwork showed the departures of departures ceremony program, let the audience have to exclamation important ceremony in Japanese culture. Departures every movement in the process of departures, each expression is a masterpiece, even if the work is not recognized by the society, they still hold their own responsibility, as a sacrifice to strictly control every detail, not only shows the respect for the dead and the families of the dead, is also a love of life. As a cellist Xiao Lin, interpretation for every living life the beauty of music, and as the departures of Xiao Lin, is to create beautiful for each life.

And people in Japan are a people pay great attention to detail element, reflected in the movie the departures of the ritual process is the most powerful proof of [5]. In the film, departures every subtle movements show the respect for the dead and care for life. Using disinfection liquid medicine carefully for wiping the body for the dead and for the dead shave - wearing colorful clothes - beautiful and serene makeup - into the coffin, every small action has certain connotation, are manifestations of ceremony details. Can be seen from the working nature of departures, departures work the most important thing is that should be showed high respect to the dead and the families of the dead, by looking at the portrait of the deceased, use of magic make-up techniques, the maximum let the dead to restore to the original appearance, and let the body to change the power of life, to the next stage.

In the second half of the film, the hero realize from the father's hands get white stone at that moment, the story really to orgasm, is not only a hero, all the film appreciator must also will be moved by small pebbles in bearing life force. Milquetoast hero, always cannot get respect in society, even into the dead man to accept the trust of the families of the dead in the home when making up, also will be affected by discrimination, but when he really starts to work, will be in strict accordance with the departures of ritual, gently with the hand holding the hands of the dead, with a kind of awe touched the forehead of the dead face, wipe the body for them, and put on beautiful clothes, brush their hair for the children, for the woman point lipstick... At this time, he is a great, noble, let the family to realize their loved ones entrusted to a trustworthy departure.

Departures both in the film, and in real life, is to help the dead on the last journey, attitude to worship a dead, is the departures industry every worker must have the basic professional ethics. Film over and over again with almost real images to people reflects the departures of Japanese departures program, every step, every movement to be able to see the performer in the finely crafted, not only show respect for the dead, but also a concern for life. In the minds of the Japanese, nothing remains more worthy of respect, because that is the final proof of a person alive. Therefore, the departure in essence is a noble profession, who help the dead to covered last journey.

The departures ceremony in Japan departures a sweet and delicate, when the makeup for a wife, Xiao Lin to strive for perfection, for the dead point on her favorite lipstick; For a man in the body is but the mind is actually belong to the girls make up in the process, he was careful to solicit the opinions of the parents, for the sake of the dead, choose men's or women's clothing; For an old woman after painting makeup, for she is the most cherished before his death on the collar. Should realize that human life is always to the end of the life, every people will one day become off or be off, death, is not necessarily the terror, also can be beautiful and dignified, even the same as in the film performance, is happy, and relatively serious, gentle departures ceremony, then with infinite grief and respect for the living to the dead. 


\section{Conclusion}

To sum up, "departures" subject this film mainly reflects the Japanese culture life and death rituals and ceremonies in the plot, its central idea is to allow the audience to understand the departures, understand the true meaning of life, and love life, respect life, correctly understand the relationship between life and death, only then can with positive and optimistic attitude towards life, fully display its value and significance of life.

\section{References}

[1] You Ling. "departures" in Japanese culture main body. Journal of Yan An journal of vocational and technical college,2011,25(6):125-127.

[2] Wang Yi. Analyses of Japanese film "departures" art of life. Journal of literary life, literature and art theory,2014(4):152-152.

[3] Hao Chunjing, Wang Xiao Lin, Ma Yue etc. Put on death culture - Japanese film "departures" about it. Journal of intelligence,2011(11):171.

[4] Liu Xuejun. Introduction of Japanese "dead" culture, connotation of the film "departures" thinking[J]. Grand view weekly, 2011(13):51-51.

[5] Yang Ning. The Japanese culture elements analysis of "Departures". Journal of Changchun college of education,2014(11):40-41. 